\title{
Özürlü Sağlık Kurulunda Değerlendirilen Hastaların Lokomotor Sistem Özürlülüklerinin incelenmesi
}

\author{
Examination of the Patient's Locomotor System Disability Evaluated in the Board of \\ Health for Disabled
}

Rabia Terzi, Firuzan Altın*

Derince Eğitim ve Araştırma Hastanesi, Fiziksel Tıp ve Rehabilitasyon Kliniği, Kocaeli, Türkiye *Esenler Medipol Üniversitesi Araştırma Hastanesi, Fiziksel Tıp ve Rehabilitasyon Kliniği, İstanbul, Türkiye

\section{Özet}

Amaç: Amacımız, hastanemiz özürlü sağlık kuruluna başvuran ve lokomotor sistem ile ilgili özürlülük oranlarına sahip hastaların özelliklerini değerlendirmek ve diğer sistem özürlülükleriyle birlikteliklerini, tüm vücut fonksiyon kayıp oranlarını ve bu parametrelerin yaşlara göre dağılımını incelemektir.

Gereç ve Yöntem: Mart 2012-Mart 2013 tarihleri arasında Derince Eğitim ve Araştırma Hastanesi Sağlık Kurulu'na başvuran 2263 olgu retrospektif olarak tarandı. Lokomotor sisteme ait tanı alımış 672 hastanın, tüm branşlarca yapılmış muayene bulguları ve tanıları Sağlık Kurulu dosyalarından ayrıntılı olarak tarandı.

Bulgular: Özürlü sağlık kuruluna başvuran 2263 olgunun 672'sinde $(\% 29,6)$ lokomotor sistem patolojisi mevcuttu. Bu hastaların 366'si

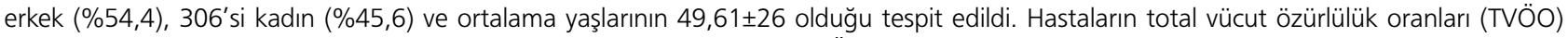


$(\% 56,3)$ Sağlık Kurulu'nca ağır özürlü olarak değerlendirildi. Beş yüz elli dördünün $(\% 82,4)$ özürlülüğü sürekli olarak raporlandırıldı. LMSÖO en yüksek 10-19 yaş aralığındaki bireylerde, en az ise 40-49 yaş aralığındaki bireylerde tespit edildi. En sık tespit edilen lokomotor sistem patolojisi sırasıyla osteoartrit (OA), hemipleji, serebral palsi, eklem kontraktürü ve spinal kord hastalıkları olarak bulundu. En yüksek LMSÖO'nun spinal kord hastalarında bulunduğu tespit edilmiştir. Lokomotor sistem özürlülüklerine en sık eşlik eden tanılar nörojenik mesane, mental retardasyon ve hipertansiyon olarak tespit edildi.

Sonuç: Özürlü sağlık kuruluna başvuran ve lokomotor sistem özürlülüğü bulunan bireylerin büyük çoğunluğu sürekli ve ağır özürlü bireylerdir. Lokomotor sistem özürlülükleriyle birlikte diğer sistem özürlülüklerinin de sıkça birlikteliğinin gözlenmiş olması, bu hastalara verilecek sosyal destek ve tedavi planlanması açısından öneme sahiptir. (Türk Osteoporoz Dergisi 2014;20: 60-4)

Anahtar kelimeler: Fiziksel engellilik, muskuloskeletal anomali, özürlü değerlendirme

\section{Summary}

Objective: Our goal was to evaluate patients who admitted to Board of Health for Disabled in our hospital, and evaluate the characteristics and disability rates of patients with locomotor disability. Also to examine its co-occurrence with other system disabilities, the whole body function loss rates and the distribution of these parameters according to age.

Materials and Methods: Medical records of 2263 cases admitted to the Board of Health in Derince Training and Research Hospital were retrospectively analyzed between March 2012 and March 2013. Examinational findings and diagnoses of 672 (29.6\%) patients who took diagnosis related with locomotor system were reviewed.

Results: Of the 2263 patients admitted to the board of health for disabled, 672 (29.6\%) had locomotor system pathology. Of these patients, 366 were males $(54.4 \%), 306$ were females $(45.6 \%)$ and the mean age was $49.6 \pm 26$ years. The mean total body disability rates of the patients (TBDR) were 69.5 \pm 28.4 , while the locomotor system disability rates (LSDR) was $49.43 \pm 17.1$. Of the 672 patients, 379 (56.3\%) were assessed as severely disabled by the medical council. 554 patients (82.4\%) had permanent disability. LSDR was highest in individuals aged 10-19 years; lowest in the individuals aged 40-49 years. The most commonly detected locomotor system pathologies were osteoarthritis $(\mathrm{OA})$, hemiplegia, cerebral palsy, joint contractures and spinal cord diseases. The highest LSDR was in the spinal cord injury patients. The most frequent comorbid diagnoses were neurogenic bladder, mental retardation, and hypertension.

Conclusion: Most of the patients who admitted to the Board of Health for locomotor system disability had permanent and severe disabilities. Observing that other system disabilities are frequently concomitant with locomotor system disability is important in terms of the social support for these patients and for planning of the appropriate treatment. (Turkish Journal of Osteoporosis 2014;20: 60-4)

Key words: Physical disability, musculoskeletal anomaly, disability evaluation

Yazışma Adresi/Address for Correspondence: Dr. Rabia Terzi, Derince Eğitim ve Araştırma Hastanesi, Fiziksel Tıp ve Rehabilitasyon Kliniği, Kocaeli, Türkiye GSM: +90 5053515572 E-posta: drrabia1@yahoo.com Geliș Tarihi/Received: 14.03.2014 Kabul Tarihi/Accepted: 09.05.2014

Türk Osteoporoz Dergisi, Galenos Yayınevi tarafindan basılmıştır. / Turkish Journal of Osteoporosis, published by Galenos Publishing. 


\section{Giriş}

Özürlü; doğuştan veya sonradan; bedensel, zihinsel, ruhsal, duyusal ve sosyal yeteneklerini çeşitli derecelerde kaybetmesi nedeniyle, toplumsal yaşama uyum sağlama ve günlük gereksinimlerini karşılamada güçlükleri olan, korunma, bakım, rehabilitasyon ve destek hizmetlerine ihtiyaç duyan kişi olarak tanımlanmaktadır (1). Özürlülük bireyleri, aileleri ve sosyal toplumu yakından etkileyen bir durumdur (2). Rehabilitasyon kliniklerinde kişinin yetersizliklerinin, kaybedilmiş, bazen de limitlenmiş olan fonksiyonel kapasitesinin belirlenerek tedavi edilmesi, psikososyal ve mesleki yönde de desteklenerek günlük yaşamda bağımsız duruma getirilmesi amaçlanmıştır. Bu anlamda Fiziksel Tıp ve Rehabilitasyon branşı; özürlü hasta grubuyla sıkça ilgilenen ve bu hastaların sorunlarına çözüm aradığı bir branştır.

Lokomotor sistem kayıplarının koruyucu ve tedavi edici hizmetlerle en alt düzeye indirilmesi; özürlü bireylere en uygun rehabilitasyon yöntemlerinin uygulanarak yaşama katılmalarının sağlanması ve hak ettikleri sosyal güvenceye sahip olması süreçlerinin tümünde fiziyatristlerin önemli katkısı bulunmaktadır. Ülkemizde bir çok hasta sosyal haklarını kullanabilmek için çeşitli hastanelerdeki Özürlü Sağlık Kurulları́na başvurmaktadır. Özürlüler ile ilgili olarak bu kurulların verileri önemli bir kaynak olabilir. Sağlık Kurulu raporları ayrıntılı tıbbi incelemenin yapıldığı ve kayıt altına alındığı kurullar olması nedeniyle önemli bir veri bankasıdır. Lokomotor sistem özür oranı (LMSÖO) ile tüm vücut özür oranı (TVÖO) ilişkisinin belirlenmesi de, özellikle sosyal güvenlik ile ilgili desteklerin daha bilimsel ölçütlerle yapılmasına katkı sağlayabilir. Amacımız hastanemiz özürlü sağlık kuruluna başvuran ve lokomotor sistem ile ilgili özürlülük oranlarına sahip hastaların özelliklerini değerlendirmek ve diğer sistem özürlülükleriyle birlikteliklerini, tüm vücut fonksiyon kayıp oranlarını ve bu parametrelerin yaşlara göre dağılımını incelemektir. Özürlülüğe neden olabilecek lokomotor sistem hastalıklarının belirlenmesinin bununla birlikte diğer sistem özürlülüklerinin hangi sıklıkta ve neler olduğunun bilinmesinin özellikle branşımızı ilgilendiren lokomotor sisteme ait özürlü hasta grubuna yaklaşım ve patolojileri önlemede gerekli tedbirlerin alınması açısından faydalı olacağı düşünülmüştür. Lokomotor sistem patolojileriyle özürlülüğe neden olan diğer sistem patolojilerinin neler olduğunun bilinmesi özürlü hastaya multidisipliner yaklaşım açısından önemlidir.

\section{Gereç ve Yöntem}

Mart 2012-Mart 2013 tarihleri arasında hastanemiz özürlü sağlık kuruluna başvuran 2263 olgu retrospektif olarak değerlendirildi. Lokomotor sisteme ait tanı almış 672 hasta çalışmaya alındı. Bu hastaların tüm branşlarca yapılmış muayene bulguları ayrıntılı olarak tarandı. Tarama sağlık kurulu dosyalarının incelenmesi ile gerçekleştirildi. Tüm hastaların demografik verileri, başvuru amaçları kaydedildi. Hastaların, başta lokomotor sistem hastalıkları olmak üzere tüm hastalıklarıyla ilgili tanıları ve bunlara ait özürlülük oranları, özür durumlarının ağır ve sürekli olup olmadığı, başvuru nedenleri kaydedildi. Değerlendirme, resmi gazetede yayınlanan "Özürlülük ölçütü, sınıflaması ve özürlülere verilecek Sağlık Kurulu raporları hakkında yönetmelik" ile özürlülük oranları hesaplanarak yapıldı. Ağır özürlü: Yönetmelikte belirtilen şekliyle "Özür durumuna göre özür oranı \%50 ve üzerinde olduğu tespit edilenlerden günlük yaşam aktivitelerini başkalarının yardımı olmaksızın yerine getiremeyeceğine özürlü sağlık kurulu tarafından karar verilen kişiler" olarak değerlendirilmiştir. İstatistiksel analizler için SPSS version 10.0 paket programı kullanıldı. Verilerin değerlendirilmesinde tanımlayıcı istatistiksel metotları (ortalama, standart sapma) uygulandı. Çalışma için Kocaeli Üniversitesi'nden Etik Kurul onayı alındı.

\section{Bulgular}

Özürlü sağlık kuruluna bir yıllık süre içerisinde başvuran 2263 olgunun 672'sinde $(\% 29,6)$ lokomotor sistem patolojisi mevcuttu. Bu hastaların 366'sı erkek (\%54,4), 306'sı kadın $(\% 45,6)$ idi. Ortalama yaşlarının 49,6 26 olduğu tespit edildi. On sekiz yaş altındaki birey sayısı $63(\% 9,3)$ iken, 65 yaş üzerindeki hasta sayısı $208(\% 30,9)$ olarak bulundu. Hastaların TVÖO

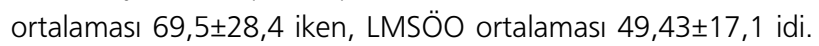
Altı yüz yetmiş iki hastanın $379^{\prime} u(\% 56,3)$ Sağlık Kurulu'nca ağır özürlü olarak değerlendirildi, 554'ünün $(\% 82,4)$ özürlülüğü sürekli olarak raporlandırılı. Özürlü sağlık kuruluna en sık başvuru nedeni sosyal yardım ve evde bakım hizmetlerinden

\section{Tablo 1. Özürlü sağlık kuruluna başvuru nedenleri}

\begin{tabular}{|l|l|l|}
\hline Başvuru nedeni & $\mathbf{n = 6 7 2}$ & $\%$ \\
\hline Sosyal yardım/Evde bakım hizmetlerinden yararlanma & 269 & 40,02 \\
\hline Çeşitli nedenlerle özür derecesini bildirir rapor talebi & 162 & 24,1 \\
\hline Özel eğitim başvurusu & 76 & 11,3 \\
\hline 2022 sayılı yasadan yararlanmak & 45 & 6,69 \\
\hline ÖTV indirimi & 42 & 6,25 \\
\hline Özürlü araç ehliyeti talebi & 34 & 5,05 \\
\hline Akülü tekerlekli sandalye başvurusu & 9 & 1,3 \\
\hline Huzur evi- Bakım evine yerleşme nedeniyle & 4 & 0,5 \\
\hline Birden fazla talep & 31 & 4,6 \\
\hline
\end{tabular}


yararlanma talebi nedeniyle yapılmıştı. Başvuru nedenleri Tablo 1 'de özetlenmiştir.

Tüm vücut özür oranı en yüksek 90 yaş ve üzerinde, en az ise 40-49 yaş aralığındaki hastalarda tespit edildi. LMSÖO en yüksek 10-19 yaş aralığındaki bireylerde, en az ise 40-49 yaş aralığındaki bireylerde tespit edildi. Yaş gruplarına göre özürlülük oranları ve ağır özürlülüğe sahip birey sayıları Tablo 2'de verilmiştir.

Altı yüz yetmiş iki hasta içerisinde en sık tespit edilen lokomotor sistem patolojisi osteoartrit (OA) olarak bulundu. Yüz yirmi dokuz $(\% 19,2)$ OA tespit edilen hastanın 60'ında diz OA'sı, 11'inde kalça OA'sı, 12'sinde diz ve kalça OA'sı, 23 hastada omurga OA'sı, 23 hastada da jenaralize OA mevcuttu. Yüz yedi hastada hemipleji tespit edildi. Hastaların 65'i sol, 42'si sağ hemiplejikti. Doksan bir hasta serebral palsi (SP) tanısı almıştır. Altmış iki hasta spastik SP, 18 hastada diskinetik SP, üç hastada mikst tip SP saptanmış olup sekiz hastada ise SP tipi belirtilmemişti. Yetmiş hastada travma, fraktür ya da immobilizasyon gibi nedenlerle gelişmiş eklem kontraktürü saptanmış olup, bunların 39'u alt ekstremitede, 31'i üst ekstremitede tespit edilmiştir. En sık diz, kalça, dirsek eklemlerinde tespit edilmiştir. Altmış üç hastada spinal kord lezyonu tespit edilmiş olup, bu hastaların 43'ü paraplejik, 20'si tetraplejikti. Kırk dokuz hastada periferik sinir yaralanması mevcuttu. On sekiz hastada brakial pleksus lezyonu, 13 hastada siyatik sinir yaralanması, sekiz hastada median sinir, dört hastada ulnar, üç hastada radial sinir, üç hastada median ve ulnar sinir yaralanması tespit edildi. Otuz dokuz hastada çeşitli seviyelerde ampütasyon mevcuttu. Yirmi beş hastada alt ekstremitede, 14 hastada üst ekstremitede ampütasyon tespit edildi. Yaş ortalaması en yüksek grubun $O A$ tanısı alan grup oluğu, en düşük grubun ise serebral palsi tanılı hastalar olduğu görüldü. Spinal kord hastalıkları en yüksek LMSÖO ve TVÖO'ya sahip iken, eklem kontraktürü tanısı olan hasta grubu en az LMSÖO ve TVÖO'ya sahipti. TVÖO ile LMSÖO arasında en az farka sahip gruplar; polio sekeli hastaları ile eklem kontraktürü olan hasta grubu idi. Tablo 3'te en sık görülen lokomotor sistem patolojileri ile özürlülük oranları belirtilmişsir. Lokomotor sistem özürlülüğü bulunan 91 hastada nörolojik tanı da mevcuttu. En sık nörolojik tanılar sırasıyla Demans ( $n=52)$, Epilepsi $(n=20)$, Parkinson $(n=10)$ olarak tespit edildi. Lokomotor sistem özürlülüğü bulunan 52 hastada göz patolojisi tespit edildi. En sık tanılar sırasıyla görme bozukluğu ( $n=25)$, diabetik retinopati $(n=10)$ ve glokom $(n=10)$ olarak bulundu. Altmış üç hastada kulak burun boğaz patolojisi bulundu. En sık tanılar sırasıyla tek kulakta işitme kaybı ( $n=20)$, iki kulakta işitme kaybı $(n=18)$ ve konuşma bozuklukları $(n=11)$ olarak bulunmuştur. Iki yüz üç hastada iç hastalıklarıyla ilgili tanı mevcuttu. Yetmiş beş hasta birden fazla dahili tanıya sahipti. En sık tanılar sırasıyla hipertansiyon $(n=74)$, hiperlipidemi ve hipertansiyon $(n=74)$, diabet $(n=31)$ olarak saptandı. Yüz yetmiş iki hastada ürolojik tanı tespit edildi. En sık tanılar sırasıyla nörojenik mesane $(n=140)$, stres inkontinans $(n=22)$, prostat bezi hastalıkları $(n=17)$ olarak tespit edildi. Yüz elli bir hastada psikiyatrik tanı tespit edildi. En sık tanılar sırasıyla mental retardasyon $(n=91)$, depresyon-anksiyete $(n=22)$, organik mental bozukluk $(n=28)$ olarak tespit edildi. Altmış üç hastada göğüs hastalıkları patolojisi izlendi en sık tanılar sırasıyla astım ( $n=39)$, kronik obstrüktif akciğer hastalığı $(n=20)$ olarak bulundu. Seksen hastada kardiyak patoloji izlendi. En sık tanılar koroner arter hastalığı $(n=30)$, kalp yemezliği $(n=25)$, ritm bozukluğu $(n=10)$ olarak tespit edildi. On dokuz hastada onkolojik tanı mevcuttu. En sık onkolojik tanılar akciğer $(n=6)$, kolon $(n=4)$, meme $(n=4)$, prostat $(n=3)$ maliniteleri olarak bulundu.

\section{Tartışma}

Özürlülüğün önlenmesi, rehabilitasyonu ve fırsat eşitliğinin sağlanması amacıyla politikaların belirlenmesi, programların planlanması, yürütülmesi ve değerlendirilmesinin önemi her geçen gün vurgulanmaktadır (3). Bu anlamda branşımızı ilgilendiren hasta grubunun Özürlü Sağlık Kurulları'na başvuru nedenlerinin, tanılarının ve bu özürlü grubun ek patolojilerinin neler olduğunun bilinmesi önemlidir. Dünya Sağlık Örgütü, gelişmiş ülkelerde nüfusun \%10'unu gelişmekte olan ülkelerde ise \%12'sini özürlülerin oluşturduğunu kabul etmektedir (4).

\section{Tablo 2. Yaş gruplarına göre tüm vücut ve lokomotor sistem özürlülük oranları}

\begin{tabular}{|l|l|l|l|l|}
\hline Yaş grupları & $\begin{array}{l}\text { Kişi sayısı } \\
\mathbf{n}(\%)\end{array}$ & $\begin{array}{l}\text { LMSÖO* } \\
\text { (Ortalama } \mathbf{n} \text { standart } \\
\text { sapma) }\end{array}$ & $\begin{array}{l}\text { TVÖO** } \\
\text { (Ortalama } \pm \text { standart } \\
\text { sapma) }\end{array}$ & Ağır özürlü kişi sayısı \\
\hline $0-9$ & $72(10,7)$ & $56,43 \pm 23,75$ & $75,01 \pm 20,18$ & 48 \\
\hline $10-19$ & $30(4,4)$ & $65,93 \pm 21,42$ & $80,73 \pm 15,2$ & 20 \\
\hline $20-29$ & $53(7,8)$ & $46,12 \pm 27,64$ & $57,42 \pm 27,5$ & 19 \\
\hline $30-39$ & $74(11,01)$ & $43,55 \pm 20,31$ & $54,90 \pm 26,5$ & 13 \\
\hline $40-49$ & $94(13,9)$ & $40,19 \pm 24,91$ & $53,38 \pm 21,84$ & 20 \\
\hline $50-59$ & $77(11,4)$ & $40,51 \pm 23,65$ & $54,10 \pm 25,4$ & 24 \\
\hline $60-69$ & $76(11,3)$ & $47,0 \pm 28,76$ & $73,36 \pm 16,2$ & 52 \\
\hline $70-79$ & $82(12,2)$ & $54,53 \pm 21,84$ & $81,69 \pm 18,7$ & 75 \\
\hline $80-89$ & $94(13,9)$ & $50,2 \pm 22,63$ & $86,41 \pm 13,45$ & 90 \\
\hline 90 ve üzeri & $20(2,9)$ & $62,45 \pm 21,26$ & $94,06 \pm 5,28$ & 18 \\
\hline *Lokomotor sistem özülülü oranı, **Tüm vücut özürlülük oranı & & \\
\hline
\end{tabular}


Ülkemizde Ulusal Özürlüler Veri Tabanına kayıtlı özürlülerin \%29,2'si zihinsel özürlüler, \%25,6'sı süreğen hastalığı olan özürlüler, $\% 8,8$ 'i ortopedik özürlüler, $\% 8,4$ 'ü görme özürlüler, \%5,9'u işitme özürlüler, \%3,9'u ruhsal açıdan özürlüler, \%0,2'si dil ve konuşma özürlüler ve \%18'i birden fazla özüre sahip olanlardır (5). Arslan ve ark.'nın yapmış oldukları 23 merkezli epidemiyolojik çalışmada Kocaeli ilinde yaşı nüfusta özürlülük $\% 16,5$ olarak tespit edilmiş ve Türkiye genelinde en az özürlülük oranına sahip il olarak belirlenmiştir (6).

Lokomotor sistem özürlülüğü ile ilgili Diyarbakır merkezinde yapılmış bir çalışmada hareket sistemi özürlülerinin sayısı 1031, toplumdaki sıklığı ise \%2,66 olarak tespit edilmiştir (7). Türkçe literatürde özürlü sağlık kuruluna başvuran hastaların lokomotor sistem patolojilerini araştıran kapsamlı bir çalışmaya rastlanmamıştır. Özürlü Sağlık Kurulları́nda kulak burun boğaz, göz ve nörolojik patolojilerin incelendiği birkaç çalışma yer almaktadır (8-10). Sırasıyla Sağlık Kurulu'na başvuran hastaların kulak burun boğaz ve nörolojik tanıya sahip olma oranları $\% 13,5$ ve \%10,87 olarak belirtilmiştir. Çalışmamızda özürlü sağlık kuruluna başvuran hastaların \%29,6'sı lokomotor sistem ile ilgili tanı alan hastalardı. Diğer çalışmalarla karşılaştııılığında lokomotor sistem patolojilerinin daha sıklıkla görüldüğü ya da Sağlık Kurulu'na daha sık başvurduğu düşünülmektedir. Bu oran, sağlık kurullarına yapılan başvurularda lokomotor sisteme ait patolojilerin değerlendirilmesi açısından hastanemize yapılan başvurular ile sınırlıdır. Hastaneye ulaşamayan, başka hastaneye başvuran, Sağlık Kurulu raporu almaya intiyaç duymayan kişiler dahil edilmediğinden genel toplumdaki lokomotor sistem özürlülük oranını yansıtmamaktadır.
Çalışmamızda lokomotor sistem patolojisi olan olguların ortalama yaşı 49,61ะ3,26 idi. Türkiye Özürlüler Araştırması'na göre özürlüler için median yaş 33,86 yıl olarak tespit edilmiş ve en sık 15-29 yaş grubunda görüldüğü bildirilmiştir $(3,11)$. Çalışmamızda özürlü sağlık kuruluna başvurmuş LMSÖO'ya sahip hastaların \%30,9'unun geriatrik yaş grubundaki hastalar olduğu tespit edildi. Ülkemizde yapılan nüfus sayımlarına göre yaşlı birey sayısı giderek artmaktadır (12). Genellikle geriatrik bir hastada özürlülüğe giden sürece etki eden çok sayıda faktör vardır. Yaşla birlikte tüm doku, organ ve sistem işlevlerinde bir takım değişiklikler olur. Fizyolojik olarak çeşitli sistemlerdeki kapasitenin, çevresel değişikliklere uyum yeteneğinin ve strese yanıt verebilme kabiliyetinin azalması yaşlı bireyin hastalıklara olan duyarlıı̆ı̆ıı arttırır. Bu duyarlıı̆ın artmasına ek olarak bir takım ekstrensek faktörlerin eklenmesi sonucunda ileri yaş popülasyonda özürlülük daha sık görülmektedir (13-15). Çalışmamızda ağır özürlü birey oranı \%56,3 idi. Uysal ve ark.'nın Özürlü Sağlık Kurulları'na başvuru yapmış hastaları inceledikleri çalışmalarında başvuruların \%21'i kas iskelet sistemine ait özür oranı olan hastalar olup, en yüksek özür oranları kas iskelet sistem muayenesine göre elde edilmişti. Tüm hastalarda ağır özürlü birey oranı \%49,4 idi (16). Çalışmamıza sadece lokomotor sistem ile ilgili özürlü bireyler dahil edildiğinden ağır özürlü birey oranımızın yüksek olduğu düşünülmüştür.

Özürlü popülasyonunda farklı bölgelerde yapılmış çalışmaların bazılarında bayanların $(7,17)$ bazılarında da erkeklerin (18) daha fazla sayıda oldukları gösterilmiştir. Çalışmamızda erkek hastalar daha fazla Sağlık Kurulu'na başvurmuşlardı.

\section{Tablo 3. En sık görülen lokomotor sistem patolojlleri ve özürlülük oranları}

\begin{tabular}{|c|c|c|c|c|}
\hline Tanı & $\begin{array}{l}\text { Sayı } \\
\text { n }\end{array}$ & $\begin{array}{l}\text { Yaş } \\
\text { Ortalama } \pm \text { standart } \\
\text { sapma }\end{array}$ & $\begin{array}{l}\text { TVÖO* } \\
\text { Ortalama } \pm \text { standart } \\
\text { sapma }\end{array}$ & $\begin{array}{l}\text { LMSÖO** } \\
\text { Ortalama } \pm \text { standart } \\
\text { sapma }\end{array}$ \\
\hline Osteoartrit & 129 & $83,67 \pm 4,49$ & $66,33 \pm 22,30$ & $37,56 \pm 29,86$ \\
\hline Hemipleji & 107 & $59,09 \pm 8,9$ & $66,9 \pm 24,61$ & $51,72 \pm 26,52$ \\
\hline Serebral palsi & 91 & $31,47 \pm 14,07$ & $68,01 \pm 27$ & $45,61 \pm 23$ \\
\hline Eklem kontraktürü & 70 & $41,88 \pm 6,9$ & $30,88 \pm 43$ & $28,75 \pm 47$ \\
\hline Spinal kort hastalıkları & 63 & $51,37 \pm 5,8$ & $76,9 \pm 19,3$ & $53,53 \pm 24,4$ \\
\hline Periferik sinir yaralanması & 49 & $36,02 \pm 2,3$ & $66,25 \pm 25,1$ & $52,61 \pm 23,5$ \\
\hline Amputasyon & 39 & $37,16 \pm 4,6$ & $71,14 \pm 22$ & $52,73 \pm 26,4$ \\
\hline Protez operasyonlu & 30 & $65,28 \pm 6,4$ & $71,08 \pm 6$ & $51,75 \pm 22,1$ \\
\hline Ankilozan spondilit & 15 & $33,21 \pm 4,89$ & $38,5 \pm 23,7$ & $29,01 \pm 17,21$ \\
\hline Konjenital kemik eklem patolojileri & 14 & $35,21 \pm 12,1$ & $76,64 \pm 21,5$ & $44,8 \pm 21,8$ \\
\hline Romatoid artrit & 13 & $42,35 \pm 4,5$ & $68,5 \pm 26,2$ & $44 \pm 20,89$ \\
\hline Doğuştan kalça çıkığı & 12 & $38,58 \pm 3,2$ & $59,6 \pm 28,1$ & $46,04 \pm 18,9$ \\
\hline Vertebral disk patoloileri & 11 & $50,21 \pm 4,29$ & $61,47 \pm 15,24$ & $44,82 \pm 11,23$ \\
\hline Polio sekeli & 11 & $40,29 \pm 33$ & $44,9 \pm 16,71$ & $42,61 \pm 18,2$ \\
\hline Skolyoz & 10 & $35,12 \pm 11,6$ & $65,12 \pm 21,6$ & $29,25 \pm 23,2$ \\
\hline Diğer & 29 & $42,81 \pm 6,7$ & $55,12 \pm 27,4$ & $45,21 \pm 19,78$ \\
\hline
\end{tabular}


Çalışmamızda LMSÖO almış hastaların büyük çoğunluğunu OA ve sırasıyla hemipleji, serebral palsi, eklem kontraktürü ve spinal kord hastalıkları tanıı hastalar oluşturmaktaydı. Bu sıralama fizik tedavi kliniğinde en sık rastlanan hastalıklar grubunu da oluşturmaktadır (19). Lokomotor sistem özürlülüğü bulunan hastalar içerisinde TVÖO en yüksek grubu spinal kord tanısı almış hastaların oluşturduğu, en yüksek LMSÖO'na sahip hastalarında spinal kord hastaları olduğu tespit edilmiştir. OA tanısı almış hasta grubu en yüksek yaş grubuna sahip hastalardı. Ülkemizde hastalık yükü çalışmalarında OA ön sıralarda (yedinci sırada ve toplam hastalık yükü içinde $\% 2,9$ ) yer almaktadır (20). OA'lı hasta grubunda LMSÖO ile TVÖO arasında fark olduğu görülmüştür. Özellikle OA tanısı almış geriatrik grup hastaların özürlülüklerinin sadece lokomotor sistem kaynaklı olmadığının bilinmesi bu hasta grubuna multidisipliner yaklaşım açısından önemlidir.

TVÖO en yüksek 90 yaş ve üzerinde, LMSÖO en yüksek grup 10-19 yaş aralığındaki grup olarak bulunmuştur. Özürlülük prevalansının yaşla artması kronik hastalıkların tanı ve tedavisinde yaşanan gelişmeler ve yaşlı popülasyonda kadınların oranının artması ile açıklanmaktadır (6). LMSÖO'nun 10-19 yaş aralığında fazla olmasının nedeni olarak bu yaş grubunda özellikle SP hastalarının sayısının fazla olması düşünülmüştür. Ülkemizde 0-18 yaş grubunda 25 milyon çocuk vardır ve bunların 3 milyonu 0-16 yaşları arasında özürlü çocuklardır (21). SP'li hastaların ek patolojilerinin de olması, özür oranını arttırmıştır. SP'li çocukların \%50-\%75'inde zihinsel gerilik ya da öğrenme bozukluğu, \%25'inde konuşma bozukluğu, \%25'inde işitme bozuklukları, \%25-\%35'inde epileptik nöbetler, \%40$\% 50$ sinde görme bozuklukları görülür (22).

Lokomotor sistem özürlülüklerine en sık eşlik eden tanılar sırasıyla dahiliye, nöroloji ve psikiyatri bölümlerinden alınan tanılardı. En sık görülen ek tanılar ise nörojenik mesane, mental retardasyon ve hipertansiyon olarak tespit edildi. Hipertansiyon; özellikle $\mathrm{OA}^{\prime} \mid \mathrm{l}$ yaşlı hastalarda, mental retardasyon; serebral palsili hastalarda, nörojen mesane ise hemipleji, spinal kord yaralanması ve serebral palsi hastalarında sıkça gözlenen tanılar olarak bulundu.

Lokomotor sistem özürlülüğü, hareket sistem sağlığı ve rehabilitasyonu hizmetleri yanında eğitim, istihdam, sosyal güvenlik gibi ekonomik ve sosyal alanları da ilgilendiren çok boyutlu bir alandır. Çalışmamızda lokomotor sistem özürlülüğü olan hastalar en sık sosyal yardım ve evde bakım hizmetleri talebi nedeniyle özürlü sağlık raporu başvurusunda bulunmaktadırlar. $\mathrm{Bu}$ veriden LMSÖO sahip hastaların daha çok sosyal yardıma ihtiyacı olan bireyler olduğu sonucu da çıkarılabilir.

\section{Sonuç}

Bölgemizdeki lokomotor sistem özürlülük nedenlerinin tam bir profilini çıkarmamış olsa da, çalışmamızın bölgemiz için bir örnek oluşturduğunu düşünmekteyiz. Bu konuda yapılacak çalışmaların hem alanımızdaki patolojilerle ilgili demografik veri oluşturulması, hem de bu verilerin değerlendirilmesi ile özürlülere yönelik düzenlemelerin planlanmasında yardımcı olabileceği düşünülmüştür. Sağlık Kurulu'na başvuran ve lokomotor sistem özürlülüğü bulunan bireylerin büyük çoğunluğunun sürekli ve ağır özürlü bireyler olduğu, ve diğer sistemlere ait hastalıklarının da bulunduğunun göz önünde bulundurulması, bu hastalara verilecek sosyal destek ve tedavi planlanması açısından öneme sahiptir.

\section{Kaynaklar}

1. Özürlülük ölçütü, sınıflandırması ve özüllülere verilecek sağlık kurulu raporları hakkında yönetmelik. kurum ve kuruluş yönetmeliği (özürlüler idaresi başkanlığı) resmi gazete tarihi:2010: 27787.

2. Chermak GD. A global perspective on disability: a review of efforts to increase access and advance social integration for disabled persons. Int Disabil Stud 1990;12:123-7.

3. Türkiye Özürlüler Araştırması (Turkey Disability Survey). Devlet Istatistik Enstitüsü, 1 basım. Devlet İstatistik Enstitüsü Matbaası, Ankara, 2002

4. World health organization. disability prevention and rehabilitationtechnical report series 668. Geneva: WHO, 1981

5. Türkiye İstatistik Kurumu, Özürlülerin sorun ve beklentileriaraştırması, 2010. Ankara, http://tuikapp.tuik.gov.tr/ adnksdagitapp/adnks.zul (2010).

6. Arslan Ş, Gökçe Kutsal Y. Yaşlılarda özürlülüğün değerlendirimine yönelik çok merkezli epidemiyolojik çalışma. Geriatri 1999;2:10314.

7. Nas K, Çevik R, Gür A, Erdoğan F, Saraç A J. Diyarbakır merkezinde okul çocukları ve ailelerinde hareket sistemi özürlülerin sıklığı. Türk Fiz Tip Rehab Derg 1999;2:8-14.

8. Çabalar M, Demirtaş Tatılıdede A, Yazar T, Güveli B, Yayla V. Nörolojik hastalıkların özürlülük derecelerinin sağlık kurulunda değerlendirilmesi. Bakırköy Tıp Dergisi 2011;7:142-6.

9. Sayın I, Erdur Ö, Topçu I, Kayhan F T. Sağlık kuruluna özürlülük tespiti ve diğer nedenlerle başvuran olgularda kulak burun boğaz patolojileri ve sıklıkları: Gözlemsel bir çalısma. Kbb-Forum 2011;10:87-91.

10. Ceyhan D, Yaşar T, Demirok A, Çınal A, Esmer O,Batur M. Sağlık kurulu raporlarına göre Van bölgesinde görme özürlülük nedenleri. Turk J Ophthalmol 2012;42:131-4.

11. Akar T, Demirel B. Bir üniversite hastanesine başvuran özürlülerin analizi. Türkiye Klinikleri Adli Tıp Dergisi 2008;5:101-8.

12. DiE. Türkiye istatistik yıllığı, Devlet İstatistik Enstitüsü, Ankara, 2004.

13. Özgül A. Geriatrik patolojinin esasları. ın: Beyazova m, GökçeKutsal Y, Editors. Fiziksel Tıp ve Rehabilitasyon. Ankara: Güneş Kitabevi, 2000.p:1341-52.

14. Ania Lafuente BJ, Suarez Almenara JL, Guerra Hernandez. Healthy aging and functional disability among elderly inhabitants of Canary Islands (Spain). Rev Esp Salud Publica 1997;71:161-71.

15. Rosa TE, Benicio MH, Latorre M Lima F D. Determinant factors of functional status among elderly. Rev Saude Publica 2003;37:40-8.

16. Uysal C, Bulut M, Kaya C,Güneş M, Bez Y, Zeren C. Dicle üniversitesi hastaneleri özürlü kuruluna başvuran olguların incelenmesi. Adli Tıp Dergisi 2013; 27:1-9.

17. Turhanoğlu AD, Saka G, Karabulut Z. Diyarbakır il merkezinde yaşayan 65 yaş ve üzeri bireylerde özürlülük ve kronik hastalık sıklığı. Geriatri 2000;3:146-50.

18. Beşer E, Atasoylu G, Akgör Ş, Ergin F, Çullu E. Aydın il merkezinde özürlülük prevalansı, etyolojisi ve sosyal boyutu. TSK Koruyucu Hekimlik Bülteni, 2006;5:267-75.

19. Borman $\mathrm{P}$, Bodur $\mathrm{H}$. Fizik tedavi ve rehabilitasyon polikliniğine başvuran yaşlıların tanısal dağılımı. Geriatri 1999;2:57-60.

20. Ünüvar N, Mollahaliloğlu S, Yardım n (eds). Türkiye Hastalık Yükü çalışması 2004. TC Sağlık Bakanlığı, Refik Saydam Hıfzıssıhha Merkezi Başkanlığı, Hıfzıssıhha Mektebi Müdürlüğü. Aydoğdu Ofset Matbaacilık Ltd, Ankara 2007:701

21. Türkiye İstatistik Kurumu. Türkiye Özürlüler Araştırması,2002.10 ekim 2008: http://www.die.gov.tr/cın/stat/ dozurlulukorani.doc.

22. Shepherd RB. Cerebral palsy. In: Physiotherapy in paediatrics. 3rd ed. Oxford: Butterworth-Heinemann; 1995. p. 110-44. 